CuPAUAM. 20, 1993, pp. 107-131

\title{
TRANSPORTE MARITIMO DEL METAL COMO MATERIA PRIMA DURANTE EL BRONCE FINAL
}

\author{
M.ª Rosario lucas Pellicer \\ PABLO GOMEZ RAMOS \\ Universidad Autónoma de Madrid.
}

\section{Resumen}

Presentamos una descripción sumaria de los pecios del Bronce Final con cargamentos de lingotes y chatarra localizados en el Atlántico y en el Mediterráneo, así como una reflexión sobre la diversidad de tipos de lingotes y los mecanismos del comercio marítimo del metal.

Igualmente se valora el papel de las islas del Mediterráneo Central y de la Península lbérica en las conexiones mediterráneas con el Bronce Atlántico.

Palabras clave: Pecios. Bronce Final. Lingotes. Comercio marítimo.

\begin{abstract}
We introduce a summarized description about the shipwrecks from the Late Bronze Age which carried ingots and scrap metal. These were found in the Atlantic ocean and the Mediterranean sea. Also it includes a discussion about the different types of ingots and the mechanisms through which the maritime trade with metal was done.

This work also deals with the importance of the Central Mediterranean Island and the Iberian Peninsula in the mediterranean connections with the so called Atlantic Late Bronze Age.
\end{abstract}

Key words: Shipwrecks. Late Bronze Age. Ingots. Maritime trade.

Los pecios atribuidos a la etapa final del Bronce son escasos pero muy significativos por la importancia cualitativa y cuantitariva de sus materiales, y por la particularidad de que los localizados en el Mediterráneo, los más documentados, pertenecen a barcos cuya mercancia principal se relaciona directamente con el transporte y tráfico de materia prima para elaborar objetos de metal. La misma interpretación se hace 
extensiva a ciertos depósitos procedentes del Atlántico, aunque en este caso la intencionalidad es más discutida. Con todo, teniendo en cuenta que el Bronce Final en Occidente es el paradigma de un periodo cultural dominado por el énfasis en los elementos metálicos, el análisis de estos conjuntos es una fuente inapreciable para estudiar el comercio marítimo y las rutas y circuitos económicos implicados en el transporte del metal. La bibliografía generada es muy amplia y nuestra intención no es otra que trazar un panorama del estado de la cuestión e interrelacionar, sea suscintamente, una parte de la documentación generada con vistas a determinar, entre otros aspectos, la repercusión potencial del tráfico marítimo del metal en las corrientes de flujo y reflujo que por vía atlántica y mediterránea confluyeron en la Península Ibérica.

\section{RELACION DE PECIOS Y MERCANCIA TRANSPORTADA (Fig. 1.1)}

\section{A. Atlántico}

Los pecios de esta fachada occidental deben ser numerosos a juzgar por algunas noticias y hallazgos aislados que hacen sospechar de orros tantos barcos hundidos (Dean, 1984) pero la información es muy desigual ya que se trata de lotes de objetos localizados en circustancias mal documentadas y sin claras evidencias de la existencia de los barcos. A tenor de la bibliografía no podemos obviar dos conjuntos procedentes del Canal de la Mancha ni tampoco el bien conocido depósito español de la Ría de Huelva.

\section{Langdon Bay, Dover (Gran Bretaña)}

Localizado en 1964 al Este del puerto de Dover.

Ref.: MUCKelroy, 1980 y 1981; NFF.dha.M y DF.AN, 1987.

Según Needham y Dean, hasta 1983 se había recuperado un total de 352 objetos (enteros y fragmentados) concentrados en una misma zona y con un peso de 60 kilos. Se trata de bronces de composición binaria homogénea y representan una diversidad de objetos mayor que la de cualquier depósito del Bronce Final I:

Armas: 178 piezas ( espadas, hojas de puñal y 7 puntas de lanza).

Herramientas: 68 hachas de aletas medias y 8 fragmentos; 49 de talón; 18 de cubo y 8 cinceles.

Adorno personal: 10 objetos (fragmentos de alfileres, pulseras...)

Cronologia: hacia 1200-1100 a.C.

Discusión: las armas se incluyen en el grupo francés de Rosnoën y el conjunto guarda semejanzas con depósitos hallados entre el Sena y el Marne y entre el Rhin y Mainz (Coombs, 1976: 194). Esta continentalidad tipológica de materiales corrientes en Bretańa y norte de Francia, pero poco representados en las Islas Británicas, llevó a pensar que el barco naufragado transportara desde las costas francesas un cargamento de objetos en desuso (chatarra) para su refundición en las islas, sin embargo, teniendo en cuenta la homogeneidad del origen, Needham y Dean (1988) centran su atención en las hachas de tipo Taunton-Hademarschen y postulan su distribución, con vistas al comercio, desde algún taller situado en el norte de Francia. 

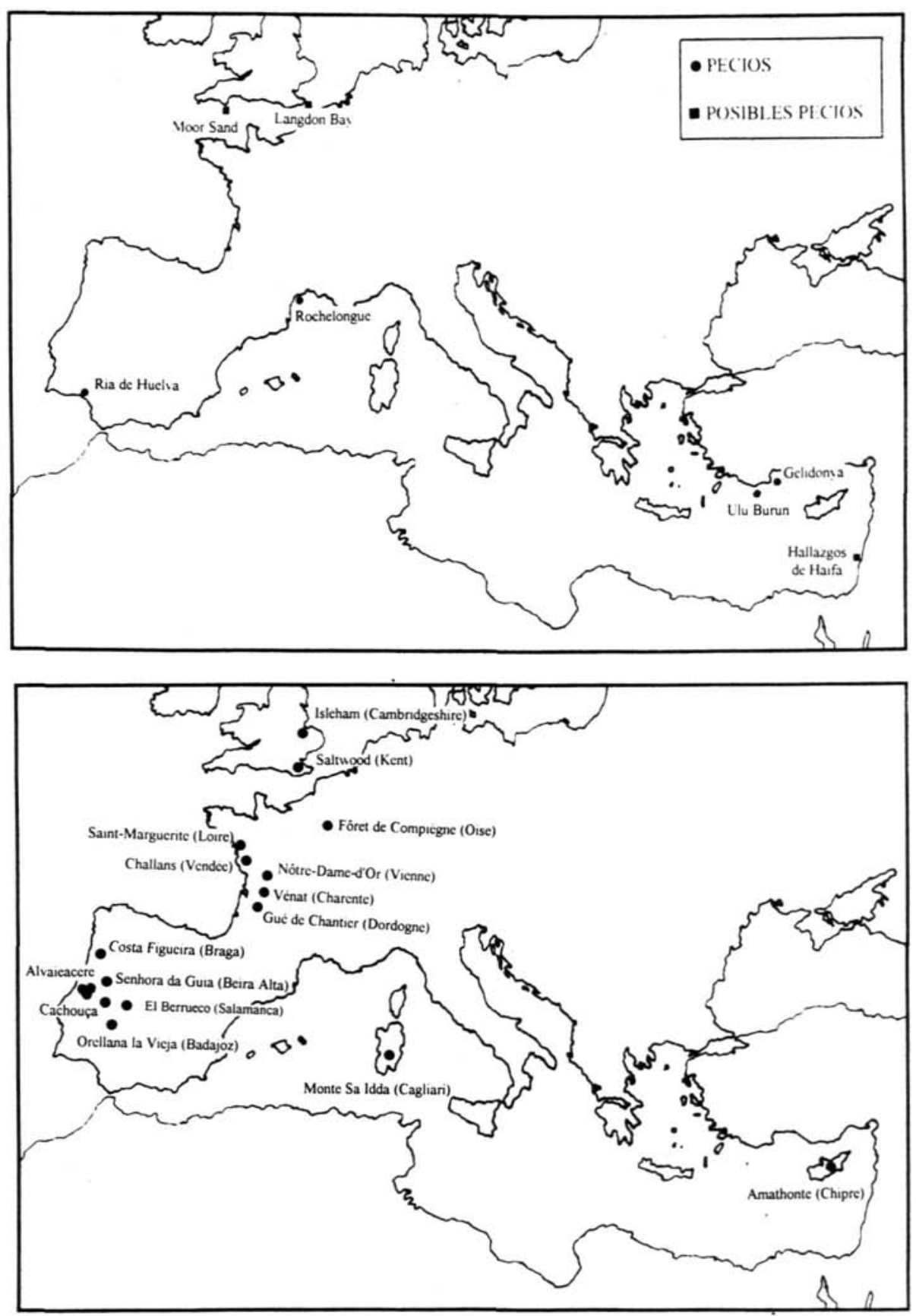

Figura 1. 1. Localización de pecios. 2. Dispersión de asadores articulados de tipología atlántica 


\section{Moor Sand, Salcombe, cerca de Devon (Gran Bretaña)}

Localizado en Salcombe, al Este de Devon, entre 1977 y 1979. Ref.: MUCKELROY y BAKER, 1979; MUCKELROY, 1980 y 1981.

Sólo se han recuperado 7 objetos:

Armas: 4 hojas y 1 espada.

Herramientas: 2 hachas de talón.

Cronologia entre el Bronce Medio III y el Bronce Final II, ajustándose la fecha hacia el siglo XII a.C.

Discusión: la tipología de los objetos es claramente continental y más en concreto francesa; estos paralelos plantean idéntica discusión que los hallazgos de Dover.

El descubrimiento marino de un hacha de talón y un fragmento de torta de fundición en Seafordd, Sussex (Dean, 1984,78) puede testimoniar otro naufragio.

\section{Ria de Huelva}

Depósito localizado en 1923 en el puerto de Huelva, al sur del muelle de Tharsis y fondo del estuario del río Odiel.

Ref.: entre otros, y con bibliografía anterior, COFFYN, 1985 y RUIZ-GÁLVEZ, 1993.

Compuesto por más de 300 piezas identificables y un centenar de fragmentos diversos, con predomio neto de bronces de composición binaria (Rovira, e.p.):

Armas. 95 puntas de lanza, 78 espadas (enteras y fragmentadas), 64 regatones, 31 puñales, 17 puntas de flecha y 3 cuchillos.

Cascos. 5 fragmentos.

Piezas de arnés. 14 botones, 10 anillas y 53 clavos.

Adorno personal: 4 fíbulas de codo completas y otros fragmentos; 2 supuestos broches de cinturón $\mathrm{y}$ algunos alfileres (?).

Herramientas: 1 escoplo, 1 punzón o lezna y 1 aguja.

Diversos. numerosos fragmentos indeterminados entre ellos varias decenas de cilindros macizos, 5 varillas y una chapita repujada. Se menciona además la "presencia de algunos hilos de hierro" (Carriazo, 1947, 801).

Cronologia: datación por C-14 de varios astiles de regatón fechan este conjunto entre el 2830$2800 \pm 70$ B.P., hacia $880-850$ a.C. y, en cualquier caso, durante el Bronce final III.

Discusión: desde el clásico artículo de M. Almagro (1950) a la bibliografía más reciente, se reconoce en las armas la fuerza de los modelos atlánticos e incluso continentales, mientras las fíbulas se relacionan con la corriente mediterránea, coincidiendo unas y otras con su representación en las estelas del Suroeste.

Durante años se ha supuesto que se trataba del cargamento de un barco hundido que transportaba objetos en desuso con destino a la refundición. Gómez Moreno (1923) apoyándose en la homogeniedad del lote, mellas de uso y reparaciones en las espadas, con ausencia de hachas y otros útiles, apuntó la posibilidad de que los objetos procedieran de "un campo de batalla" y Carriazo, por su parte $(1947,798)$ sugirió la alternativa de que el lote estuviera destinado " a las gentes de guerra" pues aunque las señales de uso eran evidentes "los bronces no están muy oxidados, las espadas conservan sus filos y, a veces, la punta; las fibulas pueden usarse todavia...". 
En efecto, en el conjunto priman los implementos bélicos, complementados con un número menor de piezas atribuibles al manejo del caballo y al ornato personal, elementos que en su mayoría pueden calificarse como de prestigio. A tenor de los objetos mejor identificados pueden reducirse a dos categorías:

a) Armamento, auténtica panoplia, representada en proporción equivalente a un hipotético ejército de su tiempo (menor proporción de cascos y de posibles pertrechos de caballo que de armas para utilizar a pie, incluyendo el empleo de arcos).

b) Adornos poco corrientes y en escaso número destinados a vestimenta de rango o de lujo.

Ultimamente, argumentando semejanzas con los depósitos acuáticos del Noroeste de Europa, Ruiz Gálvez (1991 a y 1993) atribuye al depósito de Huelva el carácter votivo de ofrenda a las aguas. Esta interpretación de ritual es sugestiva y tiende a explicar la singularidad del conjunto, pero la aparente coetanidad de materiales, impropia de tal práctica, y la rareza del ritual en la Península Ibérica, deja abierta la hipótesis a otros eventos que podrían estar relacionados tanto con sucesos bélicos (naufragio, debelación de armas...) como con circunstancias más rutinarias del transporte de mercancías, por lo que la interpretación del cargamento de un barco no puede darse por zanjada. Más adelante retomaremos el tema.

\section{A. Mediterraneo oriental}

Los pecios más significativos y mejor estudiados proceden de las costas meridionales de Turquía. Sobre su importancia basta recordar el protagonismo de los dos principales pecios, Ulu Burun y Gelidonya en la Conferencia celebrada en Rewley House, Oxford, en 1989 (Actas editadas por N. H. Gale en 1991). A ellos hay que unir otros hallazgos peor documentados localizados en la costa norte de Israel, en los alrededores de la ciudad de Haifa.

\section{Ulu Burun, Kas (Turquia) (Fig. 2)}

Descubierto en 1982, a menos de un kilómetro al noreste del cabo de Ulu Burun, cerca de Kas, antigua Licia en la actual Turquía. Ha sido recuperado sistemáticamente desde 1984 por el Instituto de Arqueología Naútica de Texas.

Ref.: BASS, 1986 y 1991; PUIAK, 1988; BASS et alii: 1989.

El cargamento se caracteriza por la procedencia heterogénea de las mercancías (mínimo de siete lugares diferentes desde el Báltico a Nubia) y de su naturaleza; ha sido posible incluso determinar los vegetales (Haldane, 1993) utilizados en el embalaje y protección de la carga cuyo peso se estima en más de 10 toneladas.

Materias primas: cerca de seis toneladas de cobre y estaño en bruto, distribuidas en más de 200 lingotes ( algunos con marcas) de "piel de buey" y un buen número de forma plano-convexa mientras que sólo 1 lingote de estaño adoptaba forma prismática-rectangular. Estaban acomodados entre capas de plantas para amortiguar golpes y es la primera vez que se documenta la existencia de lingotes de estaño con forma de piel de buey. A estas materias hay que unir docenas de discos o lingotes de cristal de color azul de origen sirio-palestino; marfil en bruto de hipopótamo y elefante; huevos de avestruz; madera de ébano del Africa Ecuatorial; ámbar del Báltico y caparazones de tortuga. 


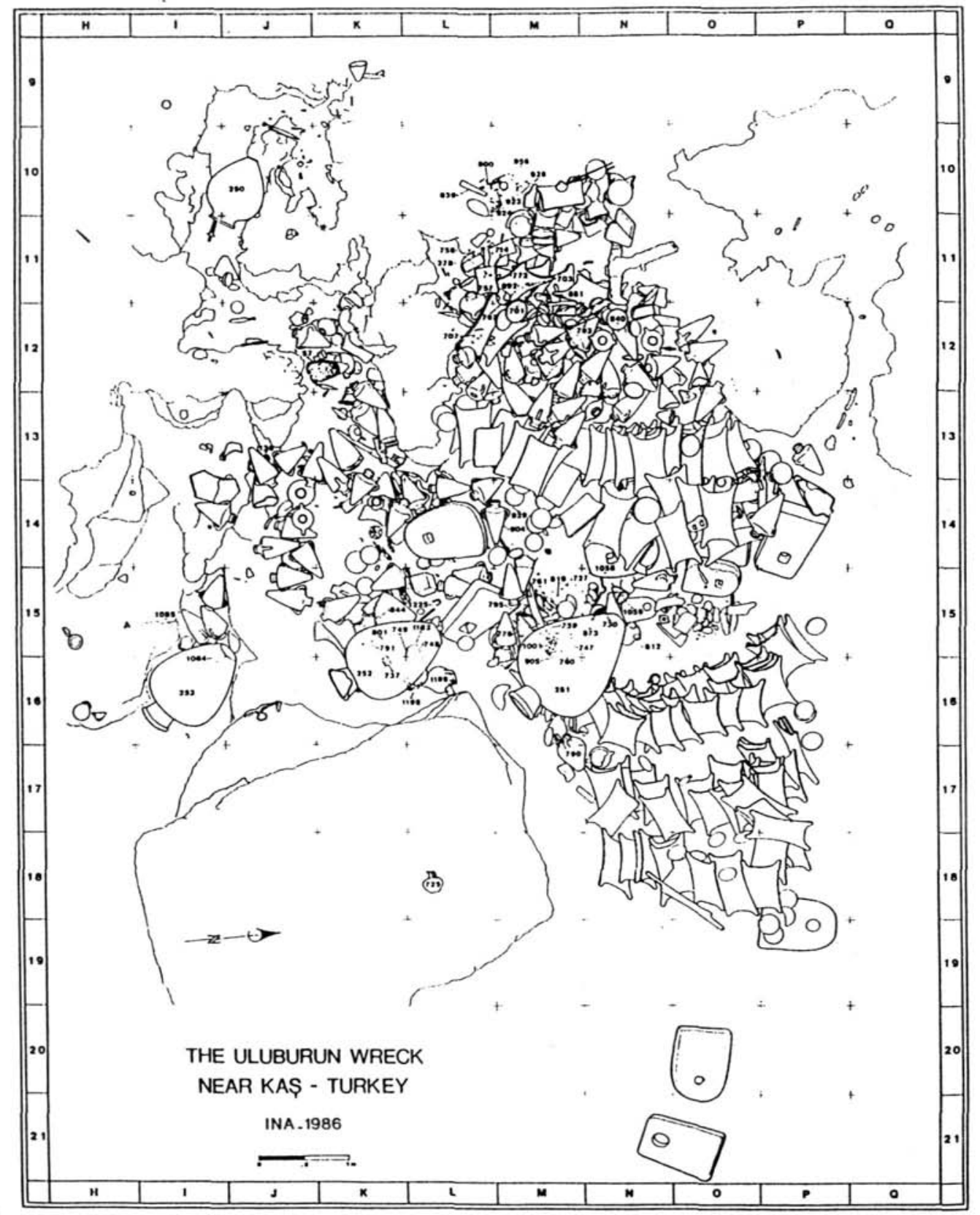

Figura 2. Disposición de la carga en el pecio de Ulu Burun. Turquia (scgún Bass et alii, 1989) 
En contenedores cerámicos (en su mayoría pithoi cananeos) se transportaba mirra para perfumes procedente de la Península Arábiga, resina Aluida de terebinto (casi una tonelada) con el mismo destino, ya procesada (¿de Siria?); oropimente (trisulfido de arsénico) y murex opercula para fabricar pigmentos

Especias, frutos y alimentos: además de miel, los envases cerámicos contenían cilantro, azafrán, comino negro, granadas, uvas, higos, aceitunas... Frutos secos (almendras y nueces) cereales y leguminosas pueden testimoniar la dieta de a bordo (Haldane, 1993, 357).

El análisis de restos orgánicos está proporcionando un caudal insospechado de datos ( Haldane, 1993), demostrando que se comercializan comestibles, pero sobre todo vegetales que pueden relacionarse con la fabricación de perfumes.

Armas. de bronce y muy numerosas, con predominio de tipos egeos y cananeos. Además de puñales y dagas, puntas de flecha, lanzas etc., destacan espadas de diferentes tamaños. Una de ellas micénica y otra de tipo Thapsos-Pertosa procedente de Sicilia o del sur de Italia.

Adorno personat joyas de oro y plata de diversas procedencias. A saber, un anillo de oro con jeroglíficos egipcios, un medallón de oro y brazaletes de plata de origen cananeo y dos escarabeos, uno de ellos de Nefertiti. La fragmentación y el mal estado de las piezas sugieren la refundición como destino. También se localizó un importante número de cuentas de ámbar, fayenza, hueso y piedra, así como un alfiler micénico.

Herramientas: entre los útiles de trabajo, también de bronce y de tipología fundamentalmente sirio-palestina, se identifican hachas, azuelas, cinceles y pinzas. Estas herramientas estaban en su mayor parte enteras y en buen estado de conservación.

Cerámica. 120 ánforas de tipo cananeo contenan la resina de terebinto ( se estima un peso de 9 kilos por ánfora). En identicos contenedores se localizaron también lámparas de procedencia sirio-palestina, jarras de estribo ( posibles recipientes de perfume), copas y un kylix de factura micénica, además de otras piezas de posible origen chipriota.

Diversos. ritones de fayenza y pesos de red y balanzas (algunos de tipo zoomorfo); sellos de diversas materias y culturas: micénica, chipriota, egipcia, babilónica (reutilizado por un asirio) y kasita. Por último, cabe señalar entre la variedad de objetos la existencia de un díptico, el más antiguo de los "libros" conocidos, formado por dos planchas enceradas de madera unidas por bisagras cilíndricas de márfil, que apareció almacenado junto con granadas en un pithos cananeo.

Cronologia. la cerámica micénica (Heládico Reciente III A2-B) y las joyas egipcias de la XVIII dinastía fechan este barco hacia fines del siglo XIV a.C.

Discusión: la diversidad cultural y geográfica de estas mercancías es un serio obstáculo a la hora de precisar nacionalidad y recorrido del barco, aunque se cree que seguía una ruta Este-Oeste. Según Bass (1991: 74), las piedras para las anclas, cerámicas e incluso el díptico de madera sugieren como nacionalidad del mercante el área levantina del Próximo Oriente, aunque Pulak aboga por una procedencia micénica en razón de las posesiones de abordo y del avituallamiento. Los sellos por su parte, apuntan a la pertenencia personal de comerciantes de distintas procedencias embarcados en la nave. En cualquier caso el lujo y exotismo de la carga concuerda con las exigencias de una corte aulica, sobre todo teniendo en cuenta la importante cantidad de la materia prima de metal (como chatarra se consideran únicamente las joyas) y las sustancias destinadas a perfumes y ungüentos (a decir de Haldane a este fin podrían destinarse ademàs de la resina de terebinto, las olivas, el cilantro, e incluso las granadas). 


\section{Cabo de Gelidonya (Turquia)}

El hallazgo se produjo en 1959, a la altura del cabo de Gelidonya, en el suroeste de la costa de Anatolia. Fue excavado por G. Bass y Throckmorton a partir de 1960.

Ref.: BASS, 1967 y 1991.

El peso del cargamento es menor que el anterior, aproximándose la carga de metal a una tonelada. Al igual que en el pecio de Ulu Burun, las mercancías son muy variadas y estaban cuidadosamente apiladas y envueltas en diferentes contendores orgánicos.

Materia prima en lingotes. es el volumen más pesado del cargamento y está compuesto por 39 lingotes ( 34 enteros y 5 mitades) de cobre en forma de piel de buey, la mayor parte de ellos con marcas (Fig. 3.4). A la misma morfología pertenecen 12 extremos y 75 kilos de fragmentos. Las tortas planoconvexas de cobre son 12 completas, 8 casi entereras y 9 mitades, además de numerosos fragmentos, probablemente almacenados en cestos. Se recuperaron 19 lingotes en barra amontonados en filas de 3 ó 4 lingotes cada una. Son en mayora de cobre aunque la composición de una de ellas era bronce ( $5,27 \%$ de $\mathrm{Sn}$ ). Unos 8 kilos de polvo blanco (óxido de estaño) se interpretan, como restos de lingotes de estaño.

Armas y otros fragmentos de bronce. puntas de lanza y hojas de dagas y puñales, todas ellas fragmentadas, posiblemente chipriotas aunque es difícil precisar su origen. También se identifican una navaja de afeitar, una espátula, un asador, varios brazaletes, anillos, garfios, trípodes, etc. Estos elementos estaban destinados a la refundición y se hallaron en cestos y canastas de mimbre, rotos o incompletos, agrupados por categorías y mezclados con fragmentos de lingores.

Herramientas: con actividades agrícolas se relacionan picos, palas, azadas, rejas de arado, etc., y con el trabajo de la madera útiles como hachas dobles y azuelas. Al equipo de un metalúrgico pertenece un cincel, un punzón, un pequeño yunque de bronce, tres piedras utilizadas como tal y dos mazas también de piedra. La mayoría de estos instrumentos se considera de origen chipriota. Morteros, cabezas de maza, pulidores, martillos de piedra, etc. completan el conjunto.

Elementos personales: un sello cilíndrico de origen sirio se atribuye al mercader responsable de las transacciones. También se consideran elementos de la tripulación 5 escarabeos, imitaciones sirio-palestinas de piezas egipcias.

Cerámica: un número indeterminado de jarras de almacenaje, recipientes de estribo (alguno de ellos con resina de terebinto para perfumes) y otras vasijas, de fabricación chipriota o siria y micénica; fragmentos de cuencos y una lámpara de factura sirio-palestina (destinada, quizá, al servicio del barco).

Diversos. 60 pequeños objeros de piedra y de metal de diferentes formas testimonian distintos juegos de pesos de balanza; fragmentos de cristal de roca, cuentas de collar, huesos de aceitunas, raspas de pescado... son otros tantos elementos de abordo.

Cronologia: segunda mitad del siglo XIII o inicios del XII a.C. Según Gale $(1991,204)$ circa 1240 1200 a.C.

Discusión: el aprovisionamiento de metal en materia prima y chatarra es la base del cargamento. Bass no descarta que el barco llevase un metalúrgico ambulante y sostiene la hipótesis de que este flete representa " la aventura privada de un mercader levantino que acabó en Cabo Gelidonya al final del siglo XIII a.C., especialmente si se considera a Chipre como parte del Levante" $(1991,74)$. Para Maddin y Muhly $(1974,25)$ estamos ante una empresa comercial organizada, y Knapp $(1993,335)$ considerando 


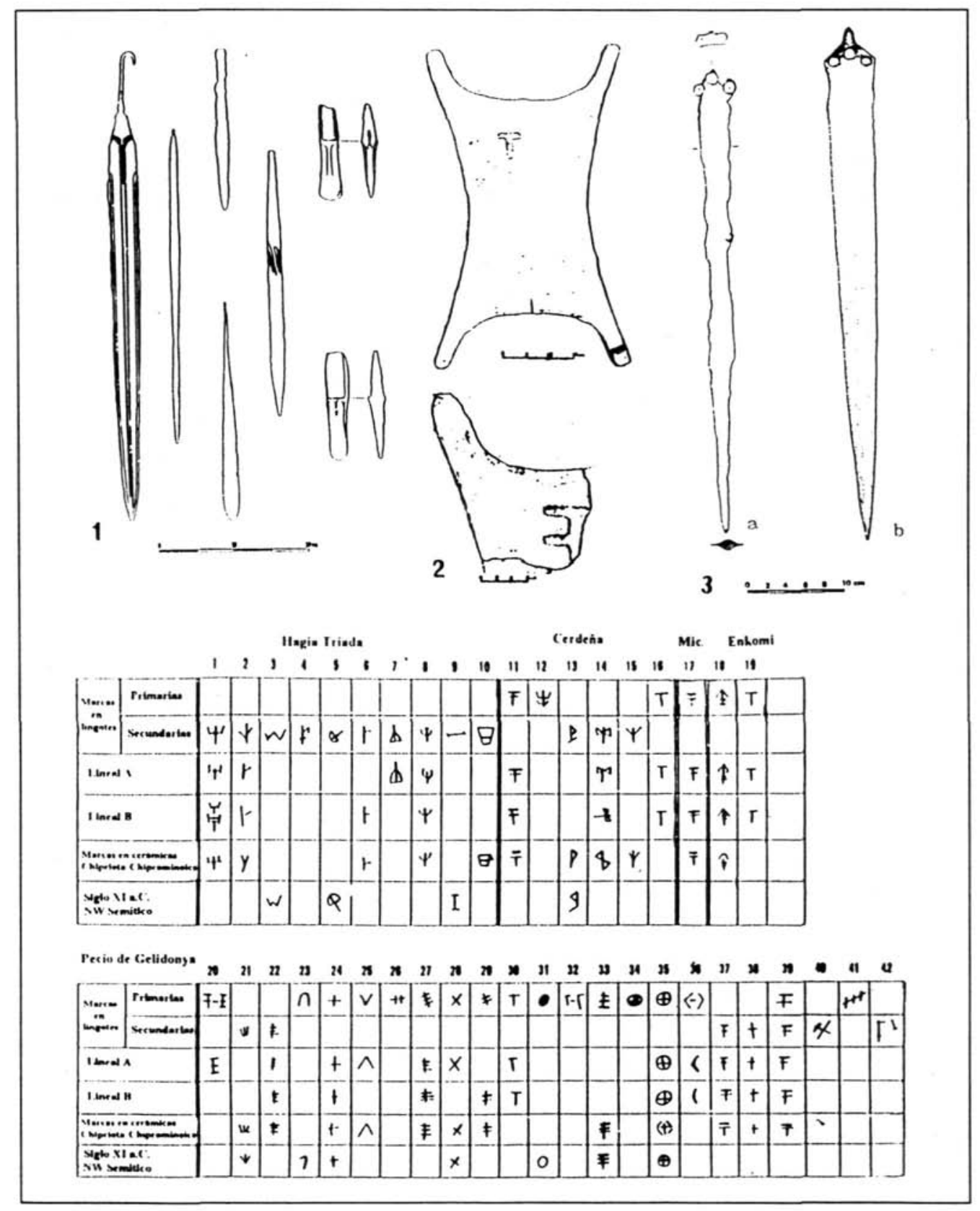

Figum 3. 1. Materiales procedentes de Moor Sand (scgún Muckelroy, 1980). 2. Lingotes sardos con marcas primarias (según Vagnetti y Lo Schiavo, 1989). 3. Fspadas tipo Thapsos-Pertosa, a: Ulu Burun, b:Matrensa, Sicilia (según Vagnetti y Lo Schiavo, 1989).

4. Contrastación de marcas de lingotes entre cjemplos mediterráneos y hallazgos de Gelidonya (según Bass, 1967) 
las evidencias materiales del barco y los adornos personales predominantemente sirios, apunta que aunque los orígenes étnicos y el puerto de origen sean inciertos, podría tratarse de una actividad de comerciantes actuando en su propio beneficio.

La ejemplar recuperación de los pecios de Ulu Burun y Gelidonya y lo notable de sus cargamentos abren la posibilidad de que también testimonien otros tantos pecios una serie de lingotes y materiales recogidos en aguas próximas: cerca de Side, en 1913 se rescataron dos lingotes de cobre fechados en los siglos XVI-XV, y otro en Deveboynu Burnu, datado hacia 1200 a.C. (Bass, 1986, 270-271).

\section{Haifa, Israel}

Otros descubrimientos submarinos en la costa norte de Israel, cerca de la ciudad de Haifa, donde la ausencia de puertos naturales ha convertido el lugar en un auténtico cementerio de barcos naufragados, indican la presencia de otros pecios, hasta el momento menos afortunados en la investigación. Los relativos a esta época son:

3.1. Ha-Hotrin, al Sur de Haifa. En 1980 se rescató un pequeño lote de materiales y dos anclas de piedra.

Ref.: WACHSMSNN y RAVEH, 1984.

Lingotes: fragmentos de cobre en forma de piel de buey, uno de ellos de plomo.

Herramientas: restos de un cincel, de un posible arado y un bocado de caballo. Estos materiales, cortados ya en la antigüedad, abogan, una vez más, por barcos transportadores de chatarra.

Cronologia: siglos XIII-XII a.C.

3.2. Cerca de Haifa se descubrieron en 1982 los restos del cargamento de un posible pecio.

Ref.: Galit.l, Shmuel.I y ARI7y, 1986.

Materia prima. fragmentos de 5 lingotes de estaño de sección plano-convexa, cortados de antiguo. Tres de ellos llevaban marcas incisas en silábico cipro-minoico.

Cronologia: difícil de precisar con exacritud aunque se sitúa entre los siglos XV-XIl a.C.

3.3. En las proximidades de Haifa se encontraron dos lingotes de estaño en forma de prisma rectangular. Como en el caso anterior iban marcados con signos cipro-minoicos.

Ref.: MADDIN, WHEELFR y MUHLY: 1977.

\section{Cimé, costa Eubea}

En la costa de Eubea, a la altura de Cimé, el hallazgo de 19 lingotes de piel de buey, posiblemente de cobre, se interpreta como parte del cargamento de un pecio de final del Bronce (Wheeler, Maddin y Muhly, 1975). 


\section{Mediterráneo occidental}

\section{Rochelongue, Agde (Francia)}

El descubrimiento acaeció en el verano de 1964, en las proximidades del cabo de Agde en el Mid́́ francés, zona en la que se han hallado otros testimonios submarinos de dilatada cronología. Este pecio se adscribe generalmente al Bronce Final III B, razón por la que se incluye en este artículo, si bien, los materiales datan en su mayoría dentro del Hierro $\mathrm{I}$.

Se han recuperado un total de 1.700 objetos y unos 800 kilos de tortas o lingotes, agrupados por categorías y separados entre sí, es decir, debidamente embalados.

Ref.: Hugues, 1965; BOUSCARAS,1971, JUl.ly et alii, 1978.

Materia prima de metal: un número indeterminado de tortas circulares plano-convexas de cobre muy puro (el peso individual se sitúa entre 300 gramos y 6-7 kilos); 32 lingotes de estańo de $14 \mathrm{~cm}$. de diámetro guardados en un saco, además de plaquetas de plomo e incluso galena mineral.

Armas. destacan las arrojadizos de bronce tales como puntas de flecha y jabalinas y algunas hojas de espadas y puñales.

Herramientas: martillos y buriles de cubo se identifican como útiles de fundidor. Hachas de cubo, algunas de ellas decoradas, parecen destinadas a la venta de productos elaborados, a juzgar por su estado de conservación.

Elementos de adorno personal: lote muy variado compuesto por cadenas y colgantes, brazaletes, pendientes, discos, etc., así como broches de cinturón de placa romboidal escotada y garfio comunes en el sur de Francia y Península Ibérica, al igual que las fíbulas (entre ellas de bucle y parrilla y de doble resorte).

Diversos: botones semiesféricos de uno o dos travesaños propios de arnés de caballos; fragmentos decorados de objetos suntuarios así como otros restos de identificación más imprecisa. Respecto a otras materias sólo se menciona, sin determinar filiación, restos de oinochoes (Jully et alii, 1978: 11).

Cronologia: aunque algunas de estas piezas pueden remontarse al siglo VIII a.C. y están bien representadas, al igual que los lingotes plano-convexos, en los depósitos de ripo Launac, un importante número de objetos, entre ellos, fíbulas y broches de cinturón, es idéntico a los recuperados en ajuares de distintos ambientes del Hierro Antiguo tanto en el Mediodía de Francia como en la Península Ibérica. En función de su interpretación como piezas para comercializar o refundir, de acuerdo a la asociación de estos elementos, la cronología del naufragio puede oscilar entre fines del siglo VII y más allá del vi a.C.

Discusión : en opinión de Bouscaras (1971), principal investigador, este pecio documenta el naufragio de un fundidor que remontaría las costas de la Península Ibérica hacia el sur de Francia, recogiendo piezas "chatarra", a la vez que prestaba sus servicios y se abastecía de materia prima cuando descendiera a tierra. En razón de la pureza del cobre, de los mater, de los broches de placa escotada y de algunos tipos de fíbulas se pronuncia por un origen en el sur de la Península. Si descartamos los objetos de adorno, bien conocicos en el sur de Francia, el grueso de materiales, según las fotografías, tienen una localización muy limitada y sólo unos pocos elementos, como las cadenillas colgantes traspasan el Ebro; el resto o 
están ausentes o se ciñen a la línea del Ebro, desde el delta hasta Alava, tanto en poblados (con presencia incluso de lingotes plano-convexos) como en necrópolis calificables al Hierro I o Ibérico antiguo cuyos contextos están estrechamente vinculados al avance del horizonte Grand Bassin I y la transición al II. Incluso uno de los fragmentos de Rochelongue es muy similar en técnica y disposición al thymiaterion de Calaceite (Lucas, 1982) y a otras dos piezas prácricamente análogas de Les Payros y St. Julien de Pézenas en el sur de Francia (mitad del siglo VI a.C.)

\section{LA INTENCIONALIDAD DE LOS FLETES: MATERIA PRIMA DE METAL}

Los cargamentos de todos los barcos y posibles pecios mencionados, pese a la divergencia geográfica e incluso temporal, tienen en común, como ya se ha señalado, la evidencia de que el objetivo del flete era el aprovisionamiento de metal.

Las cuestiones implícitas en este arseto son muchas y el contraste entre lo conocido en el área oriental y occidental demuestra notables diferencias. Por consiguiente, abordaremos esta parte en distintos epígrafes con el fin de pergeñar el balance actual de la investigación e intentar dar respuestas a

preguntas tales como la modalidad adoptada por el metal para su transporte, valores metrológicos, organización del comercio, etc.

\section{LOS LINGOTES}

El transporte de metal en lingotes fue característica común en el Mediterráneo Oriental desde mediados del segundo milenio.

El pecio de Ulu Burun está entre las primeras pruebas materiales del uso de lingotes de piel de buey pero las tortas o lingotes específicos de sección plano convexas y los lingotes-barra, por este orden de preferencias, demuestran en un mismo pecio la coetaneidad de los distintos tipos para las mismas materias.

A juzgar por el fragmentario testimonio del mencionado hallazgo de Sussex, el transporte marítimo de lingotes también se practicó en el Atlántico, si bien la información más segura del área occidental proviene del pecio de Rochelongue. No obstante, y aunque no es el caso de la Península Ibérica donde el número de lingotes es muy exiguo (Gómez Ramos, 1992), depósitos terrestres y algunos yacimientos atlánticos prueban que la existencia de lingotes de variada morfología, a excepción de la forma de piel de buey, es conocida con anterioridad al Bronce Final, cuando indudablemente alcanzan su apogeo (Briard, 1976). Adentrado el primer milenio, momento en el que los intereses de la koiné colonial del Mediterráneo y los contactos etruscos confluyen en el Occidente europeo, los 800 kilos de metal en bruto del cargamento de Rochelongue adoptan exclusivamente la forma de torta o lingote plano-convexo, extendida asimismo por los depósitos Launacienses, por el valle del Ebro, Noreste y Baleares como refleja el lingote del depósito de La Sabina, en la isla de Formentera (Gómez Bellard y San Nicolás, 1988: 201-220). Lingotes plano-convexos se documentan también en el cargamento de un posible barco etrusco hallado cerca 
de la isla de Giglio y fechado hacia el 600 a.C. (Bound y Vallintine, 1983: 119), probando la persintencia del tipo a lo largo del tiempo.

En cualquier caso y no sin discusiones (Muhly, Wheeler y Maddin, 1977: 354; Pulak, 1988: 8) las modalidades morfológicas de los lingotes tienden a justificarse por razones técnicas, diferencias geográficas e incluso por la necesidad de unidades más pequeñas de cobre.

En efecto, los lingotes de torta, formados en el fondo del horno (de ahí su forma plano-convexa sin necesidad de lingotera) son los más simples, comunes incluso para masas de refundición.

Esta es la explicación de su larga cronología, preferencia occidental y dispersión geográfica. Tanto en Europa Occidental como en el Oriente (Anatolia central o Israel) esta forma se documenta con anterioridad al Bronce Final y aunque su mayor desarrollo se producirá en Europa Occidental durante el estadio III del Bronce Final, sabemos que se fabrica de manera más o menos ininterrumpida hasta la Edad Moderna. Sólo el contexto y a veces también el peso guían la cronología y la posibilidad de probar su origen (Tylecote, 1980) ${ }^{1}$.

El lingote de piel de buey exige moldes específicos. Su origen es claramente oriental. Los más antiguos son del s. XIV a.C. y su producción, a juzgar por la existencia de moldes, textos e iconografía (Garenne-Marot, 1985) remire al Próximo Oriente, Egipto y el $\mathrm{Egeo}^{2}$; pero la dispersión es mucho más amplia (figura 4) pues se han localizado en el Mar Negro y en el Mediterráneo Central. En esta última zona el número es relativamente alto y afecta muy especialmente a Cerdeña aunque se constatan en Sicilia, Lípari e Italia peninsular. La producción se agora en el s. XII a.C. y hasta la fecha no se han atestiguado en el interior de Europa ni en el área occidental ${ }^{3}$.

A la recurrencia de la misma forma de lingote para transportar diferentes metales y las variantes en peso, se une la explicación técnica: las peculiaridades de una cara áspera y otra más lisa es causa directa del enfriamiento del metal fundido. Las cuatro asas e incluso la forma, son un recurso para facilitar más cómodamente el acarreo de una masa que puede llegar a pesar hasta $40 \mathrm{kilos}^{4}$.

La morfología de los lingote-barra exige también una matriz adecuada. La amplia dispersión geográfica y las variantes (desde el Atlántico al Medirerráneo Oriental), llevan a la conjetura de producciones secundarias, fabricadas como medio para facilitar la fundición de objetos de forma alargada, tales como hojas de armas (Wheeler, Maddin y Muhly, 1975: 32), en línea con la tradición de las varillas para favorecer el trasiego de unidades más pequeñas destinadas a la fabricación de adornos y útiles menos pesados.

\footnotetext{
${ }^{1}$ La prolongación del transporte de metal en lingotes plano-convexos, más allá del mundo romano, se evidencia en el pecio de San Francisco (1527). Transportaba un cargamento de tortas de cobre y de plata, reflejo del comercio portuguts de metales desarrollado en el oeste de Africa a comienzos de la Edad Moderna (Craddock y Hook, 1987: 202-204).

2 En el palacio norte de Ras lbn Hani, en Ugarit (Siria) se halló el molde univalvo de uno de estos lingotes, fechado al final del Bronce (Lagarce et alii, 1983: 277-290) y la iconografia egipcia ilustra ampliamente la fabricación de este y otros tipos.

${ }^{3}$ En la Peninsula Ibérica no se ha documentado ningún lingote de piel de bucy. La recurrencia de su morfología en suelos y hogares culturales en la etapa orientalizante y en el lbérico Antiguo (Cástulo, Pozomoro, Cancho Roano, etc.) sugiere la persistencia del símbolo religioso documentado en la famosa divinidad del lingote procedente de Finkomi.

Respecto a la denominación de este tipo de lingotes y al tópico de su cquivalencia a un buey, la hipótesis, desde hace tiempo está descchada (Bass, 1961: 271: 1967: 70-71 y 1986: 275: Bass, Frcy y Pulak, 1984: 273; Pulak, 1988: 6, n. 68).

${ }^{4}$ En un trípode chipriota hallado en Kurión (Chipre) aparece una probable divinidad llevando a las espaldas un lingote sujeto por ambas manos y la iconografia cgipcia ilustra ampliamente esta forma de transportar lingotes.
} 


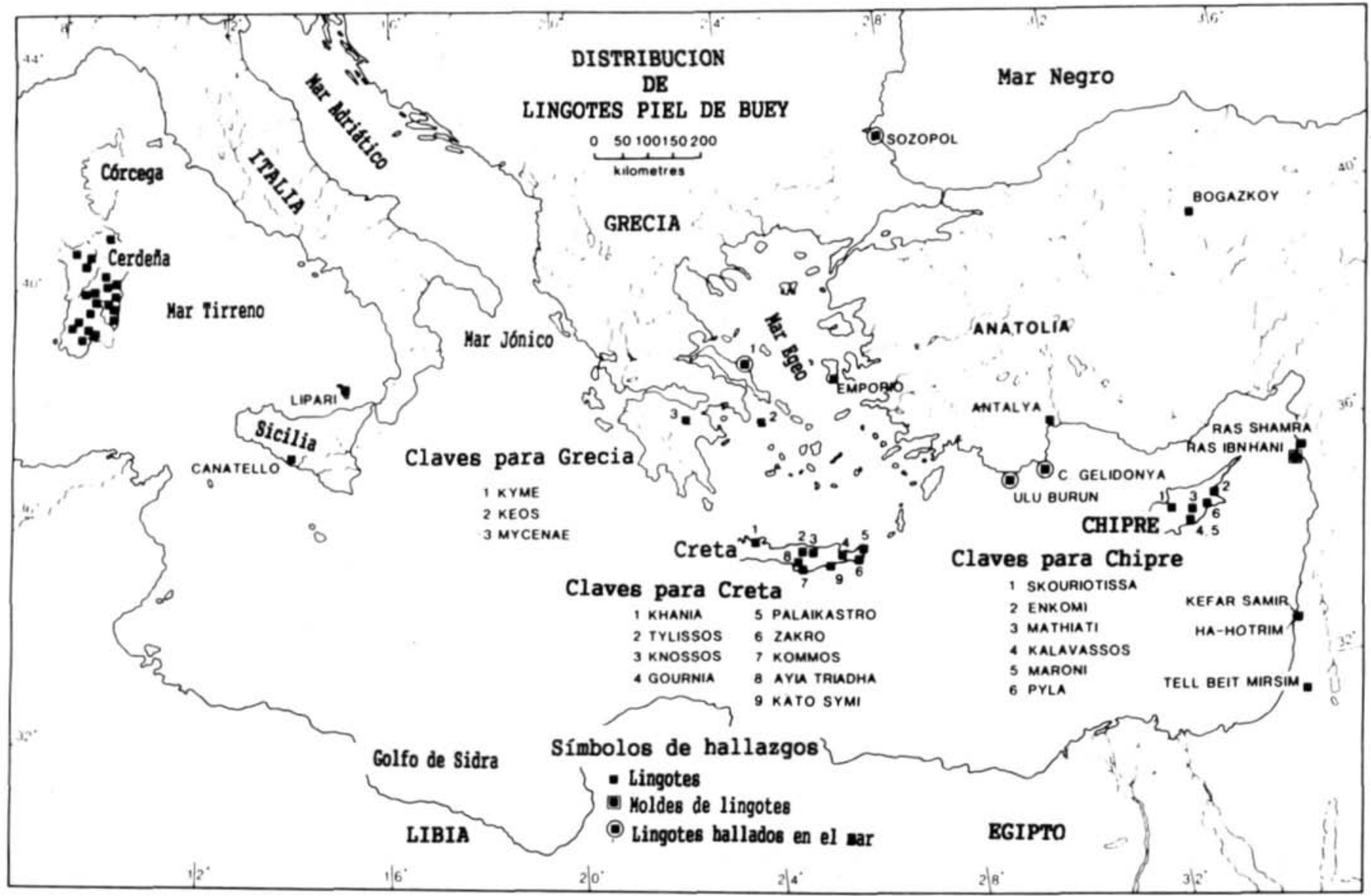

Figuna 4. Distribución de lingotes de piel de bucy (según Gale, 1991) 


\section{CHATARRA Y FUNDIDORES AMBULANTES}

En el transporte del metal por mar, el flete de lingotes se complementa, en los pecios orientales mejor conocidos, con el aporte de objetos destinados a refundición o "reciclado" aprovechando a su vez el cargamento para el traslado de otras mercancías, suntuosas en el caso de Ulu Burun, aparentemente más secundarias en Gelidonya. Conviene señalar asimismo otras diferencias: en el pecio de Ulu Burun son los materiales preciosos de las joyas los destinados a la refundición, sin presencia de chatarra mientras en Gelidonya y Ha-Hotrin, más recientes, el transporte intencionado de chatarra es bien evidente. La composición del conjunto tardío de Rochelongue parece seguir este mismo modelo en el trasiego del metal, modelo que debió de alcanzar su auge en las postrimerías del segundo milenio.

La carga de los pecios del canal de la Mancha, siguiendo rutas marinas holladas desde antiguo hicieron pensar en un transporte deliberado y exclusivo de chatarra desde las costas de Francia. En este sentido Muckleroy $(1980,101)$ observa cómo la mayoría de los estoques, puntas de lanza y hojas de Langdon Bay estaba troceada en un intento de facilitar el embalaje como materia prima. Sin embargo, algunos de los objetos del pecio de Moor Sand, también considerado como barco chatarrero, están demasiado nuevos para ser destinados a la refundición (Fig. 3.1) y la bibliografía más reciente, como ya se ha señalado, insiste en la "comercialización" de los productos franceses hacia las Islas Británicas, con la alternativa de transportar conjuntamente chatarra.

Este destino chatarrero (sin descartar la conjetura de comercializar algunos objetos) se ha atribuido durante años al depósito de Huelva, justrificando la ausencia de hachas por su escasa frecuencia en la zona del hallazgo, argumento en contradicción a lo común de estas piezas en depósitos de desecho. Ya se han señalado otras explicaciones y el tema sigue abierto pues ante la imposibilidad de discernir si las maderas asociadas al hallazgo eran o no el testimonio del barco, la clave para dirimir dudas quizás esté en revisar la funcionalidad de piezas menos valoradas, entre ellas las numerosas anillas y también los pequeños cilindros de bronce de pesos sorprendentemente uniformes, piezas normalmente marginadas en los estudios y que si no son elementos de red, cabe la hipótesis de una relación ponderal.

Por otra parte, la refundición es un hecho evidente y por mar debieron transportarse en los comienzos del siglo VIII a.C. las hachas-lingotes de los depósitos de Can' Mariano Gallet y La Sabina en Formentera con posible procedencia del taller metalúrgico de Peña Negra según propuestas de González Prats (1993, 38-39).

En resumen, la documentación, probablemente no representativa, sugiere dos modelos en el transporte marítimo del metal: en Occidente, la chatarra y los objetos elaborados preceden al comercio marítimo de lingotes. En Oriente los lingotes - metal en bruto- son la mercancía principal, los productos elaborados tienen menos importancia y la cantidad de material en desuso, a juzgar por el contraste entre el cargamento de Ulu Burun y el de Gelidonya, aumenta conforme avanza el tiempo, quizá porque a medida que se agudizan los problemas de abastecimiento y se "democratiza". el metal ( herramientas de trabajo del conjunto de Gelidonya) se da más importancia al aporte de materia prima aleada con vista a la refundición.

Otra cuestión, al hilo de estos comentarios, se centra en la posible existencia de gente armada para defender la carga y en la presencia en los barcos de fundidores expertos en la valoración del metal y en satisfacer la demanda de una clientela en tierra. 
Respecto al primer punto, es razonable pensar en la defensa de la tripulación y en la seguridad de la carga frente a actos de piratería, la hipótesis es plausible en Ulu Burun, pero hasta la fecha no está satisfactoriamente argumentada ${ }^{5}$. Respecto a los fundidores, el transporte de metal no requiere en sí mismo metalúrgicos en el sentido artesano puesto que el metal no se carga en las zonas de extracción sino en los puertos de parada. Los expertos en evaluar metal, sin embargo, son condición imprescindible y en ellos puede recaer la responsabilidad de garantizar y clasificar las mercancías. En tal sentido son obvios sus servicios y quizá, con todas sus consecuencias, la oferta o la oportunidad para la movilidad de especialistas en metal y fundidores, tanto en Oriente como en Occidente, sin que descartemos, la posibilidad de que ambas aptitudes coincidan en las mismas personas. En cualquier caso, el equipo del pecio del Cabo de Gelidonya indica claramente la presencia de un fundidor.

\section{VALORES METROLOGICOS}

El volumen de metal transportado y la intencionalidad de los cargamentos hacen sospechar de la existencia de unos módulos para las transacciones. La cuestión es más espinosa en Occidente, aunque son numerosos los autores que identifican objetos acabados como medio para estandarizar determinadas masas de metal en cánones preestablecidos, actuando por tanto con función monetal, es decir, a modo de lingotes-moneda y no como objetos en sí mismos utilitarios. Valgan como recuerdo las hachas armoricanas de plomo y los simulacros mencionados de hachas de apéndices en diversas materias procedentes de la región alicantina y Baleares (Gónzalez Prats, 1993). Esta conjetura lleva a la posibilidad de que algunas de las hachas decoradas de Rochelongue o de otros pecios occidentales tuvieran esta finalidad de lingote.

En cuanto a los pecios orientales, se acepra que los lingores representaran una forma fija de valor de intercambio, no en sentido estricto de moneda, sino en orden a la cuantificación ponderal. Pulak (1988, passim) relaciona los lingotes partidos con transacciones comerciales y señala que algunos fragmentos de piel de buey del pecio de Ulu Burun pudieron formar unidades con el valor de quadrans o un cuarto del total; también apuntan un valor referencial las mitades de este mismo tipo y de lingotes planoconvexos en el pecio de Gelidonya ${ }^{6}$.

Los lingotes-barra del Cabo de Gelidonya mantienen dos unidades fijas de 1 y 5 kg. Según Bass $(1967,82)$ esta uniformidad y su localización en la cabina, junto a las pertenencias del gobernante del barco, podrían equivaler a auténtico dinero.

La variabilidad en el peso de los diferentes lingotes de piel de buey y plano-convexos, sea en base a la fabricación local o a otras causas, no es contradictoria con estos planteamientos si se acepta la existencia de un patrón ponderal. Como argumentos convincentes están, en primer lugar, la presencia de numerosas pesas en los dos cargamentos más importantes, y por ende, su uso de acuerdo a una metrología convencional, confirmada asimismo por la asociación "metalurgia-balanza" en la iconografía egipcia y en

\footnotetext{
${ }^{5}$ Las armas del pecio de Gelidonya, en cestos y troceadas, cvidencian su valor únicamente como materia prima. En el caso de Ulu Burun, el mal estado de muchas de las armas y la procedencia distinta impiden pronunciarse abiertamente sobre si se trata de mercancías o rienen en el barco una finalidad armamentistica.

${ }^{6}$ En los Juegos Olimpicos, el vencedor del lanzamiento de disco podia premiarse con el propio disco, en ocasiones un auténtico lingote plano-convexo (Harris, 1964: 84 y ss.).
} 
los registros contables con escritura Lineal B, donde además se adopta como ideograma del metal el lingote de piel de buey; en segundo lugar, los cálculos sobre los patrones de peso, talentos, minas y siclos, derivados del canon babilónico, empleados en los textos egipcios y puestos a su vez en relación con los cargamentos de estos barcos. De acuerdo a ello el total de los lingotes de cobre de Ulu Burun, equivale aproximadamente a 183 talentos. Cantidad relacionable con los textos de El-Amarna donde se menciona el envío de 100 y 200 talentos de cobre por el rey de Alasia (reino que la mayoría de los investigadores relacionan con Chipre) (Bass, 1986, 293 y 1991, 75; PULAK, 1988, 34). Por su parte, existe enorme coincidencia entre el peso total de metal transportado en Gelidonya y el que recibían algunos talleres micénicos, según anotaciones en la tablilla Ja-749 de Pilos (Bass, 1961, 276, n. 57) ${ }^{7}$. Paradójicamente no se ha podido averiguar el módulo seguido en la articulación de las pesas procedentes de estos naufragios, lo que no implica que no fueran utilizadas en instrumentos de medida. Es más, se especula con la adopción de una metrología específica según fuera la materia.

Por último, no se puede obviar que la cuestionada relación entre la forma del lingote de piel de buey y su equivalencia a dicho animal, no invalida el valor de referencia que seguramente tuvo el buey en el ámbito egeo, como queda reflejado en varias fuentes literarias griegas ${ }^{8}$. La identificación entre este primitivo dinero y lingotes con su misma función deberá basarse, sin embargo, más en estudios ponderales que en supuestas similitudes morfológicas.

\section{ORGANIZACION Y CONTROL DEL COMERCIO}

Un aspecto a considerar en relación al control y organización comercial de la materia prima son las marcas localizadas en los lingotes, frecuentes en Oriente y testimoniadas igualmente en algunos productos de fundición del Mediterráneo Central (Fig. 3.2). En el Atlántico y Mediterráneo Occidental nada de esto se ha apuntado, pero tres lingotes-torta del pecio de Rochelongue llevan signos escritos: una especie de Y pintada y dos grabados de aspecto antropomorfo (Hugues, 1965: 176).

El significado de estas letras y dibujos incisos es controvertido. En el caso de que los lingotes hubieran funcionado como elementos de referencia, las marcas podrían indicar unos pesos concretos y por lo tanto, unos valores aceptados. Sin embargo, la variabilidad descarta la relación directa de signos con determinadas formas de lingote, materia o peso. Lingotes de Gelidonya de idéntico peso llevan marcas diferentes $\mathrm{y}$, viceversa, formas diferentes de lingote y de materia, con distintos pesos, ostentan idénticos signos en el cargamento de Ulu Burun.

En cuanto a la técnica se distingue entre marcas "primarias", hechas durante el proceso de moldeo cuando el metal todavía estaba caliente y por tanto relacionadas con el lugar de fabricación, caso de algunos lingotes de Gelidonya o de la marca elíprica de uno de los lingotes de los mencionados pecios de

${ }^{7}$ El uso de patrones ponderales utilitarios pucde constatarse en el lingote hallado en la antigua Apolonia (Bulgaria), pues tiene exactamente el mismo peso que les lingotes de piel de bucy de Hagia Triada, $29 \mathrm{~kg}$., considerado a su vez, como el peso del talento minoico (Muhly, Maddin y Whecer, 1980: 85).

${ }^{8}$ Homero relata como lacres, padre de Ulises, compró una esclava por mercancias cuyo valor ascendia a veinte bueyes (Odisea, I, 431). Por su parte, Esquilo, en su obra Agamemnón (v. 36), narra que el silencio del vigía Taltibio sobre el adulterio de Clitemnestra fue comprado con "un gran buey que pesa sobre su lengua", aludiendo a la moneda de la epoca. 
Haifa (Galili, Shmueli y Artzy, 1986: 33) y otras "secundarias", incisas en el metal ya frío, que según Pulak $(1988,36)$ se hicieron fuera del área de origen, bien en puntos de recepción o de exportación. En los lingotes de cobre de Gelidonya aparece este tipo de marcas, que para Bass (1967, passim) pueden hacer referencia al dueño de la mercancía, a los inspectores de la carga, etc. Es plausible, sin embargo, que indiquen una fórmula de garantía por parte de entidades distribuidoras, dentro del contexto de un poder centralizado, el cual comercializa y distribuye productos fabricados y obtenidos en distintas áreas geográficas.

Aunque la identificación de la grafía de muchas de las marcas recaiga en la escritura chipriota (o más en concreto en letras cipro-minoicas), todo apunta hacia una diversidad de orígenes. Por su parte los análisis metalúrgicos, con diferente fortuna y controversia, tampoco ayudan a precisar el origen y recorrido de los barcos, si bien los exámenes por isótopos de plomo están proporcionando una magnífica información sobre las fuentes de metal. Así, el cobre minoico parece llegar de Afganistán, Irán o sur de Rusia, mientras que una parte de los lingotes micénicos proviene de Chipre (Gale, 1991: 225-227).

Según Gale (1991, 228-229) el análisis de 15 lingotes del pecio de Gelidonya ratifica la procedencia chipriota del cobre y, en Ulu Burun, de los 10 lingotes analizados, nueve de diversa morfología, confirman la fuente de Chipre y sólo en uno plano-convexo se ignora el origen del cobre. Como bien enfatiza este investigador (versus Muhly) estos datos son extensibles, únicamente, a los lingotes analizados y es presumible, sobre todo en Ulu Burun, que exista cobre de diferentes fuentes.

Esto lleva a reflexionar sobre la organización y supuesto control del comercio marítimo de metal. Cuanto más sabemos mayores son las dudas acerca del monopolio minoico y micénico y ya que cada vez se da más protagonismo al levante asiático con una larga experiencia de los mercaderes de oficio, actividad fundidora en el palacio de Ras Ibn Hani, al sur de Ugarit, barrios chipriotas especializados en el trabajo del metal, etc. Por ello, aunque se tenga en cuenta que en Egipto el abastecimiento, acopio y fundición del metal está estrechamente vinculado al faraón y a los templos (incluyendo el pago de tributos) o a los palacios en el mundo minoico y micénico, la propuesta de mercaderes y navegantes, impulsados por y al servicio de estas sociedades, es compatible con la redistribución del metal, una vez llegado a su destino, sin descatar la tradición de regalos de bienes exóticos o de lujo como parte de una política diplomática entre élites (Snodgrass, 1991). Pero los mecanismos debieron ser complejos y multidimensionales, combinando diversas estrategias según fuera el momento y la ocasión. Los argumentos de Knapp (1993) desmitifican las talasocracias y apuestan por un continuado proceso de transformación de los sistemas de intercambio interregional, enlazando polírica y economía. El metal forma parte de los bienes más deseados y su demanda mediatiza la estandarización de su valor como medida de intercambio. El control por los centros del poder no puede ser negado, pero las iniciarivas empresariales y la extensión de los mercados también estimularon la acrividad mercantil.En cualquier caso, a juzgar por Ulu Burun, el coste del barco, la pericia técnica, la carga del mercante, la asunción de riesgos, etc. delatan una compleja estructura social y económica que mueve muchos ámbitos. Es más, la demanda de recursos convertibles en bienes de lujo exige el aprovisionamiento externo; las referencias textualey y la contabilidad abogan por un abastecimiento organizado y no de fortuna con mecanismos complejos y derroteros bastante fijos para

${ }^{9}$ La cita biblica referida al abastecimiento de materias preciosas en tiempos del rey Salomón deja entrever un comercio organizado y periódico: "una vez cada tres años llegaba la flota de Tarsis cargada de oro, plata, márfil, monos y pavos reales" (1 Reyes $10,22)$. 
asegurar la diversidad de materias primas y en tal sentido los puestos portuarios de Kommos en Creta y Marsa Matruch en Libia, dan buen testimonio ${ }^{10}$ al igual que Antigori en Cerdeña.

Aunque el colapso de Micenas apunte a una crisis del sistema económico del control palaciego, las empresas mercantiles estaban ya en marcha y abiertas a la iniciativa privada. La crisis, por tanto, favorecería la actividad de los "ventureros" (uno de ellos podría ser el responsable de Gelidonya, si la propuesta ya apuntada de Bass es correcta) y la isla de Chipre pudo tomar ventajas. A partir de ahora el centro catalizador del comercio no será el palacio sino el templo, y el debate sobre el trasiego marino del metal ha de centrarse entre semitas y chipriotas, sea por razones de vocación mercantil o por la reconocida importancia de Chipre como isla abastecedora del cobre y de su lugar privilegiado en las rutas del Mediterráneo.

Por el contrario, en el Bronce Final Atlántico, la competencia de prestigio entre las jefaturas de una incipiente aristocracia guerrera propició las transacciones y el estímulo de la actividad metalúrgica y del intercambio interregional, acusando en el engranaje la dolencia de un poder consolidado. Los marinos, pescadores primero, especialistas después (Muckelroy, 1980, 1981, passim) fueron el polo crucial de los mecanismos por mar, pero debemos estar en guardia ante la capacidad de conservación de los metales y la posible visión sesgada de estas actividades, así como ante la rapidez con que se introducen las novedades por vía terrestre.

Talleres como los de Fort-Harrouard (Eure-et-Loire) en Francia, el alicantino de Peña Negra en Crevillente y depósitos como el de Senhora da Guia en Baioes (Viseu) o Ría de Huelva son ejemplos de una actividad metalúrgica de cierta envergadura y aunque los datos arqueológicos son todavía precarios para asegurar las rutas o explicar convincentemente los mecanismos, el enlace entre rutas terrestres, fluviales y marinas es ciertamente obvio. La actividad metalugica debía depender en buena medida de grupos jerarquizados que controlaban las materias primas y los intercambios. "Status", especialidad artesana y ostentación de elementos de prestigio contrastan con la aceptación de chatarreros y metalurgos ambulantes, económica y socialmente independientes con anterioridad a la generalización del hierro, justamente cuando mejor sabemos que la fabricación de objetos de lujo de imitación oriental sigue actuando de elemento distintivo de las élites. Es en este contexto donde tiene cabida el pecio de Rochelongue para satisfacer la enorme demanda y producción de bronce como respuesta al auge de nuevas sociedades, impulsoras en el mediodía francés del rumbo del denominando bronce launaciense, evidenciando un comercio de materias primas destinado a los primeros comerciantes etruscos (Bouloumiè, 1992: 13-15) y en última instancia a las colonias de Occidente.

\section{INTERRELACION ORIENTE Y OCCIDENTE}

El nexo entre Oriente y Occidente se centra en el ámbito del Mediterráneo Central, donde el sur de Italia e islas de Sicilia y Cerdeña testimonian una larga relación con el Egeo, enfatizada por la presencia

${ }^{10}$ Recientes investigaciones (entre otros, A. y S. Sherratt, 1991: 371-72) interpretan como lugares de recalada en los circuitos por mar a larga distancia dos puntos concretos: por un lado el asentamiento portuario de Kommos, al oeste de Mesara (Creta) en donde se han localizado cerámicas de fabricación chipriota idénticas a las halladas en Cerdeña, anclas de piedra del mismo origen que la de los pecios rescñados y vasijas de procedencia local sarda (en este caso fechadas en el MR IIIB: 1300-1200 a.C.) y por otro, la isla de Bates en Marsa Matruch (l.ibia) donde junto a restos de actividad metalúrgica se han encontrado cáscaras de huevos de avestruz y una serie de cerámicas adscritas al HR IIIA. MR III y CR II. 
de cerámicas micénicas y por otras pruebas herereogéneas que jalonan la progresión de contactos a partir del 1600 a.C., abundando en la fuerza de lazos entre Cerdeña y Chipre, desde el s. XIII hasta traspasar posiblemente el s. $\mathrm{X}$ a.C.

Ya se ha señalado que una de las espadas del pecio de Ulu Burun (Fig. 3.3) pertenece al tipo Thapsos-Pertosa (Vagnetti-Lo Schiavo, 1989: 222) y cabe la posibilidad que el ámbar del Baltico se comercializara pasando por Italia. Tinajas comparables a los contenedores cananeos de Ulu Burun se han testimoniado en la nuraga de Antigori y materiales coincidentes con los transportados por este barco naufragado también han circulado por el Mediterráneo Central: marfil, sellos, pasta vítrea, jarras de estribo, etc. (Jones y Vagnetti, 1991). Los instrumentos de fundidor tanto de este pecio como del de Gelidonya se califican de chipriotas, al igual que los implementos de este carácter y los trípodes localizados asimismo en Cerdeña. Pero sobre todo hay que valorar un dato todavía más contundente en el protagonismo de Cerdeńa: la abundancia de lingotes de piel de buey en un unos 50 hallazgos, algunos marcados con escritura ciprominoica. Los análisis de 12 de estos lingotes sardos, según Gale (1991: 218-219 versus Muhly, Cherry y Knapp) arrojan una probabilidad estadística del $90 \%$ en favor de una fabricación con cobre chipriota producido durante el CR II-III (ss. XIV-XII a.C.) y atesorados probablemente como símbolos de estatus. En contraste, los bronces indígenas de Santa María in Paulis se realizaron con recursos cupríferos nativos de Cerdeña.

Entre los elementos de contrapartida cuentan las cerámicas de "impasto" sardo halladas en el lugar cretense de Kommos, probable fondeadero en la navegación a larga distancia, y el asador articulado de la tumba 523 del cementerio chipriota de Amathonte, fechada en el Ciprogeométrico I y más concretamente hacia el año 1000 a.C. (Karageorghis y Lo Schiavo, 1989: 16). Este objeto de adscripción atlántica (Fig. 1.2) alarga no sólo la cronología que en Occidente se atribuye a este tipo de asador sino también la distancia cubierta por el famoso molde de hacha de aletas de tipo italiano, descubierto en la Casa del Comerciante de Micenas, fechado en el s. XIII a.C. Todo sugiere, pues, la no interrupción de los contactos marítimos con el Mediterráneo Oriental y la existencia de relaciones consolidadas y no de fortuna, especialmente a través de los chipriotas.

Que esta navegación a larga distancia fue decisiva para el cambio en el Mediterráneo Central (Vagnetti, 1991: 108) parecen demostrarlo asentamientos como Thapsos y Pantálica, las innovaciones templarias de la isla de Cerdeńa y las estatuillas de bronce a la cera perdida. Para Lo Schiavo $(1990,108)$ la búsqueda de cobre, estaño occidental y tal vez hierro (precoz en medios nurágicos), pudo formar parte de las motivaciones de esta navegación desde el Oriente ${ }^{11}$.

En este contexto hay que imbricar el flujo de materiales "orientales" hasta la Península Ibérica: desde los raros testimonios de las cerámicas micénicas del Llanete de los Moros, Córdoba (Martín de la Cruz, 1992) y de las cuentas de pasta vítrea de yacimientos argáricos como Fuente Alamo (Almería) hasta novedades tan conspicuas como los modelos de fíbulas chipriotas o las de tipo Pantálica II -Cassibile-e incluso objetos indirectamente documentados como los espejos, las liras u otros elementos conocidos por la iconografía de las estelas del Bronce Final. Como elemento de reflujo está toda la gama de materiales de bronce de tipología atlántica llegados a Cerdeña y quizá a Sicilia a través de la Península Ibérica (vide,

"Los recursos de cobre de Cerdeńa parecen menos pródigos de lo que se había supuesto. Actualmente se valora la posible búsqueda del alumbre (Jones y Vagnetri. 1991) y no se desdeñan los recursos potenciales de plomo. 
numerosas publicaciones de autores como Lo Schiavo, Vagnetri, Giardino, etc.). El mencionado asador atlántico localizado en Chipre representa, por tanto, los eslabones extremos de una larga cadena. En cualquier caso, merecería la pena aplicar la analítica de isótopos de plomo y ampliar el campo de referencia sobre el cobre, restringido desde hace años por los autores extranjeros a la Sierra de Cartagena (vide bibl. en Gale, 1991) y esclarecer la fuente del estaño transportado por los pecios orientales.

La Península lbérica se vió comprometida en esta "marcha del metal" que unió indirectamente Oriente y Occidente, tal como prueban dos argumentos complementarios:

1) La constatada vinculación de la metalurgia del bronce al Atlántico durante el Bronce Final. La llegada por mar de numerosos objetos de origen atlántico se refuerza todavía más por la conexión con los materiales localizados en los pecios del canal de la Mancha: dos estoques de tipo Rösnoen dragados en la desembocadura del Ulla (Meijide, 1988: 6) y tres hachas de cubo cuadrangular de tipo Tauton-Hademarschen (Coffyn, 1985: 52) localizadas en Pontevedra (una sin lugar claro de hallazgo y dos procedentes de Santa Cristina de Vilaboa y de Puentecandelas). Modelos derivados de estas hachas se centran en tierras portuguesas y llegan hasta el depósito sardo de Monte Sa Idda, depósito bien valorado por los investigadores españoles como prueba de la conexión Península Ibérica-Mediterráneo Central. Lo Schiavo (1990) hace hincapie en la geografía privilegiada de Cerdeña como mercado mediterráneo de los bronces atlánticos y tras detallar minuciosamente los materiales que muestran estas relaciones, subraya la fabricación local remarcando que desde el siglo XI y durante los siglos X y IX a.C. Cerdeña reproduce, utiliza, imita y difunde a Sicilia e Italia continental los bronces de la Península Ibérica.

2) La constatada aportación en sentido inverso. A la valoración dada por los investigadores espańoles a las afinidades con los materiales del depósito de Monte Sa Idda, se añade el hecho de que objetos tan singulares como los del depósito del castro de Senhora da Guia en Baioes (Viseu, Portugal) —entre ellos el "tranchet", la navaja de afeitar, el asador y el soporte de bronce con ruedas y decoración de trenza- hallen su réplica en Cerdeña, como también la encuentre, por su carácter de miniatura y técnica de fabricación la pequeña vasija de oro acumulada en el amasijo de Bélmez (Perea, 1991, fig. pág. 137). En el mismo sentido cabría hablar de algunos bronces baleáricos, ampliando todavía más la ruta de las islas e incluso la posible conexión con el litoral del Sudeste ibérico.

La repercusión en la Península lbérica de este afianzamiento de interrelaciones, especialmente con Cerdeña y ésta a su vez con Chipre, dos núcleos intercentrales en la navegación mediterránea (Chapman, 1991: 350-358), lleva ineludiblemente a reflexionar sobre el debatido tema del alcance de estos contactos con anterioridad a la etapa colonial, tema en el que no vamos a entrar.

En suma, pese a todas las diferencias contrastadas, el área occidental no estuvo al margen de los mecanismos de intercambios-comercio por mar. En la erapa final del Bronce, la Península Ibérica actuó de nexo, canalizando la ruta atlántica hacia el Mediterráneo Central. En esta coyuntura, Tartessos como realidad arqueológica del cambio socioeconómico engendrado por estos estímulos, no es sino la consecuencia cultural impulsada por este comercio marítimo.

Un problema diferente plantea el pecio de Rochelongue. En principio hay que fecharlo superado el Bronce Final, uniendo los depósitos launacienses con la marcha indígena beneficiada de las más antiguas importaciones etruscas, fenicias y griegas en la franja noroccidental del Mediterráneo (Lucas, 1990).

En realidad hasta que no se conozcan mejor los materiales del pecio y con ello la fecha de los objetos más recientes o la filiación de las marcas, nada definitivo puede decirse, pero todo apunta hacia un 
depósito de fuertes afinidades con la zona del Hérault y en menor medida con la ruta del Ebro. En cualquier caso el barco hundido significa, superado el Bronce Final, la reorientación de las rutas comerciales y demuestra que el Noreste estuvo implicado en el comercio marítimo del metal que afectó al sur de Francia y que fue cubierto tempranamente por los navegantes etruscos.

\section{BIBLIOGRAFIA}

Almagro BasCH, M., 1950: "El hallazgo de la Ría de Huelva y el final de la Edad del Bronce en el Occidente de Europa", Ampurias, II, 84-143.

ARNAL, J. et alii., 1970: "Quelques fibules du dépôt marin de Rochelongue (Agde, Hérault)", Pyrenae, n. ${ }^{\circ}$, Barcelona, 53-58.

Baker, Ph., y Branigan, K., 1978: "Two Bronze Age swords from Salcombe, Devon", The International Journal of Nautical Archaeology and Underwater Exploration, vol. 7, n.* 2, 149-151.

BASS, G., 1961: "The Cape Gelidonya Wreck: Preliminary Report", American Journal of Archaeology vol. 65, 267-276.

- 1967: Cape Gelidonya: a Bronze Age shipwrek, Transactions of the American Philosophical Society, Philadelphia.

- 1986: "A Bronze Age Shipwreck ar Ulu Burun (Kas): 1984 Campaign", American Journal of Archaeo$\log x$ vol. 90, n. $3,269-296$.

- 1991: "Evidence of Trade from Bronze Age Shipwreks" en Bronze Age Trade in Mediterranean (ed. Gale), Studies in Mediterranean Archaeology, vol. XC, 69-82.

BASS, G. F.; FrEY, D. A., y PUI.AK, C., 1984: "A Late Bronze Age Shipwreck at Kas, Turkey", The International Journal of Nautical Archaeology and Underwater Exploration, vol. 13, n.o 4, 271-279.

BASS, G. et ali 1989: "The Bronze Age Shipwreck at Ulu Burun: 1986 Campaign", American Journal of Archaeology, vol. 93, n.० 1, 1-29.

Bouloumié, B., 1992: "Le commerce des étrusques dans le Midi de la Gaule", Les Dossiers d'Archéologie, n. $175,10-15$.

BOUND, M., y VALIIINTINE, R., 1983: "A wreck of possible Etruscan origin off Giglio Island", The International Journal of Nautical Archaeology and Underwater Exploration, vol. 12, n. ${ }^{\circ} 2,113-122$.

BOUSCARAS, A., 1971: "L'épave des bronzes de Rochelongues", Archeologia, n. ${ }^{\circ} 39$, 68-73.

BRADleY, R. 1990: The Passage of Arms. An Archeological Analysis of Prehistoric Hoards and Votive Deposits, Cambridge University Press.

Briard, J., 1976: "La paléométallurgie en France", en Guilaine, Jean (dir), La Préhistoire Française, Tomo II. Les civilisations néolithiques et protohistoriques de la France, C.N.R.S., París, 237-245.

CARriazo, J. DE MATA, 1947: "La Edad del Bronce" en Historia de España, dirigida por Ramón Menéndez Pidal, T. I, vol. 1. 755-852.

Coffrn, A., 1985: Le Bronze Final Atlantique dans la Péninsule Ibérique, Publications du Centre Pierre Paris, 11, Collection de la Maison des Pays Ibériques, 20, París.

Colıs, D. et alii 1975: "Les lingors d'étain del l'épave Port-Vendres II", Gallia, tomo 33, fasc. 1, París, 61-94. 
CоOмBS, D., 1975: "The Dover harbour bronze find, a Bronze Age wreck?", Archaeologia Atlantica, vol. 1, part. 2, 193-195.

Craddock, P. T., y HOOK, D. R., 1987: "Ingots from the sea: The British Museum collection of ingots", The International Journal of Nautical Archaeology and Underwater Exploration, vol. 16, n.' 3, 201-206.

CHAPMAN, R., 1991: La formación de las sociedades complejas, Ed. Crítica, Barcelona.

DEAN, M., 1984: "Evidence for possible prehistoric and Roman wrecks in British waters", The International Journal of Nautical Archaeology and Underwater Exploration, vol. 13, n.o 1, 78-79.

FERNÁNDEZ-MirANDA, M., y RUIZ-GÁlvEZ, M., 1980: "El depósito de la Ría de Huelva y su contexto cultural", Oskitania, n. ${ }^{\circ} 1$.

GALE, N. H., 1991: "Copper oxhide ingots: their origin and their place in the Bronze Age metals trade in the Mediterranean" en Bronze Age Trade in Mediterranean (ed. Gale), Studies in Mediterranean Archaeology vol. XC, 197-239.

Galili, E.; Shmueli, N., y ART'ZY, M. 1986: "Bronze Age ship's cargo of copper and tin", The International Journal of Nautical Archaeology and Underwater Exploration, vol. 15, 1, 25-37.

GARENNE-MAROT, L., 1985: "Le travail du cuivre dans l'Egypte pharaonique d'aprés les peintures et les bas-relief", Paléorient, 11-1, 85-96.

GiARDINO, C., 1987: "Sicilia e Sardegna fra la tarda età del bronzo e la prima exà del ferro. Aspetti di contatti nel Mediterraneo Centro-Occidentale nell'ambito della metallurgia", Atti del II Convegno di studi "Un millennio di relazioni.fra la Sardegna e i Paesi del Mediterraneo", 27-30 noviembre de 1986, Selargius-Cagliari, 419-427.

GOMEZ Bellard, C., y SAN NiCOI.Ás, M.a P., 1988: "La prehistoria de lbiza y Formentera: estado actual de la investigación", Trabajos de Prehistoria, 45, Madrid, 201-228.

Gómez Moreno, M., 1923: "Armas de bronce en el puerto de Huelva", Boletín de la Real Academia de la Historia, LXXXIII, 89-92.

GOMEZ Ramos, P., 1992: Lingotes de fundición en los depósitos complejos del Bronce Final de la Peninsula Ibérica, Memoria de Licenciatura inédita, Universidad Autónoma de Madrid.

GOMEZ DE SOTO, J., 1991: "Le fondeur, le trafiquant et les cuisiniers. La Broche d'Amathonte de Chypre et la chronologie absolue du Bronze Final Atlantique", en L'Age du Bronze Atlantique, Actes du ler Colloque du Parc Archéologique de Beynac, 10-14 Sept. de 1990, Ed. Mussées du Sarladais, Dordogne, 369-373.

GonZÁlez Prats, A., 1993: "La meralurgia del bronce final en el Sudeste de la Península Ibérica" en VV AA, Metalurgia en la Peninsula Ibérica durante el Primer Milenio a. C. Estado actual de la investigación, Murcia, 19-43.

Hal.DANE, C., 1993: "Direct evidence for organic cargoes in the late Bronze Age" en Ancient Trade: New perspectives (ed. J. Oares) World Archaeology 24, 3, 348- 377.

HARRIS, A. H., 1964: Greek Atheles and Atheletics, Londres.

Hugues, C., 1965: "La découverte sous-marine de Rochelongue, Agde (Hérault)", Comptes Rendus de l'Académie des Inscriptions et Belles Lettres, París, 176-178. 
JONES, R.E., y VAGNETTI, L., 1991: "Traders and Craftsmen in the Central Mediterranean: Archaelogical Evidence and Archaeometric Research", en Bronze Age Trade in Mediterranean (ed. Gale), Studies in Mediterranean Archaeology XC, 127-147.

Jully, J. et alii 1978: Agde Antique (interesa 9-11).

KARAGEORGHIS, V., y Lo SCHIAVO, F., 1989: "A west Mediterranean obelos from Amathus", Rivista di Studi Fenici, XVII, 1, 15-31.

KNAPP, P., 1993: "Thalasocracies in Bronze Age eastern mediterranean trade: making and braking a mych" en Ancient Trade: New perspectives (ed. J. OATES), World Archaeology, 24,3, 332-347

LAGARCE, J. et alii, 1983: "Les fouilles à Ras Ibn Hani en Syrie (Campagnes de 1980, 1981 et 1982). Contribution à l'étude de quelques aspects de la civilisation ugaritique", Comptes Rendus de l'Académie des Inscriptions et Belles Lettres, 249-290.

Lo SCHIAvo, F., 1980: "Wessex, Sardegna, Cipro: nuovi elementi di discussione", Atti della XXII Riuinione Scientifica nella Sardegna centro-settentruonale, 21-27 octubre de 1978, Istituto Italiano di Preistoria e Protostoria, Firenze, 341-358.

- 1991: "La Sardaigne et ses relations avec le Bronze Final Atlantique", en L'Age du Bronze Atlantique, Actes du ler Collogue du Parc Archéologique de Beynac, 10-14 Sept. de 1990, Ed. Mussées du Sarladais, Dordogne, 213-226.

LuCAS, R., 1982: "El thymiaterion de Calaceite (Teruel)", Boletín de la Asociación Española de Amigos de La Arqueologia, 16, 20-28.

- 1990: "El vaso teromorfo del Poblado Grande de Tossal Redó (Calaceite, Teruel) y su contexto arqueológico", Cuadernos de Prehistoria y Arqueologia de la UAM, 17, 169-210.

Maddin, R.; Wheeler, T. STECH, y Muhly, J. , 1977: "Tin in the Ancient Near East: Old Questions and New Finds", Expedition, 19, 2, 35-47.

MARTfN DE La CRUZ, J.C., 1992: "La Península lbérica y el Mediterráneo en el segundo milenio a.C.", en el Mundo Micénico. Cinco siglos de la primera civilización europea, 1600-1100 a.C, Museo Arqueológico Nacional de Madrid, 110-114.

MASSON, E., 1976: "A la recherche des vestiges proche-orientaux à Chipre. Fin du Bronze Moyen et début du Bronze Recente", Archäologischer Anzeiger, 139-165.

MEIJIDE, G., 988: Las espadas del Bronce Final en la Península Ibérica, ed. Arqueohistórica, 1.

MOHEN, J.-P., 1992: Metalurgia Prehistórica. Introducción a la paleometalurgia, Ed. Masson, Barcelona.

MuCKelroY, K., 1980: "Two Bronze Age cargoes in British waters", Antiquity, LIV, 211, 100-109.

- 1981: "Middle Bronze Age trade between Britain and Europe: a maritime perspective", Proceedings of the Prehistoric Society, 47, 275-297.

Muckelroy, K., y BAKER, PH., 1979: "The Bronce Age site off Moor Sand, near Salcombe, Devon. An interim report on the 1978 season", The International Journal of Nautical Archaeology and Underwater Exploration, 8, 3, 189-210.

MuHLY, J. D., 1985: "Sources of Tin and the Beginnings of Bronze Metallurgy", American Journal of Archaeology, 89, n. ${ }^{\circ} 2,275-291$.

- 1991: "The Development of Copper Metallurgy in Late Bronze Age Cyprus", en Bronze Age Trade in Mediterranean (ed. Gale), Studies in Mediterranean Archaeology XC, 180-196. 
Muhly, J. D.; Wheeler, T. STECh, y Maddin, R., 1977: "The Cape Gelidonya Shipwreck and the Bronze Age Metals Trade in the Eastern Mediterranean", Journal of Field Archaeology 4, 3, 353-362. Muhly, J. D.; MADDIN, R., y WhEELER, T. STECH, 1980: "The oxhide ingors from Enkomi and Mathiati and Late Bronce Age copper smelting in Cyprus", Report of the Department of Antiquities Cyprus, 84-99.

NEEDHAM, S., y DEAN, M., 1987: "La cargaison de Langdon Bay à Douvres (Grand-Bretagne). La signification pour les échanges à travers la Manche", en Les Relations entre le continent et les iles Britanniques à l'Age du Bronze, Actes du Colloque de Lille dans le Cadre du 22 ème Congrès Préhistorique de France, 2-7 Septembre, 1984, Revue Archeologique de Picardie, 119-124.

PEREA, A., 1991: Orfeberia prerromana.Arqueologia del oro. Madrid.

PULAK, C., 1988: "The Bronze Age Sphipwreck at Ulu Burun, Turkey: 1985 Campaign", American Journal of Archaeology 92, 1, 1-37.

PUlaK, C. y Frey, D. A. 1985: "The Search for a Bronze Age Shipwreck", Archaeology 38, 4, 18-24.

ROVIRA, S., e.p. "De metalurgia tartésica" en Tartessos. 25 años después, 1968-1993, Congreso Conmemorativo del V Symposium Internacional de Prehistoria Peninsular, Jerez de la Frontera, 1993.

RUIZ-GÁlVEZ, M., 1986: "Navegación y comercio entre el Atlántico y el Mediterráneo a fines de la Edad del Bronce", Trabajos de Prehistoria, 43, Madrid, 9-42.

- 1991 a: Recensión a "The Passage of Arms. An Archaeological analysis of hoards and votive deposits" por R. Bradley, Trabajos de Prehistoria, 48, Madrid, 434-436.

- 1991 b: "Songs of a Wayfaring Lad. Late Bronze Age Atlantic exchange and the building of the regional identy in the west Iberian Peninsula", Oxford Journal of Archaeology 10, 3, 277-306.

- 1993: "El Occidente de la Península Ibérica, punto de encuentro entre el Mediterráneo y el Atlántico a fines de la Edad del Bronce", Complutum, 4, 41-68.

ShERrATT, A., y S., 1991: "From luxuries to commodities: the Nature of Mediterranean Bronze Age Trading Systems", en Bronze Age Trade in Mediterranean (ed. Gale), Studies in Mediterranean Archaeo$\log x \mathrm{XC}, 351-385$.

- 1993: "The growth of the mediterranean economy in the early first millennium BC" en Ancient Trade: new perspectives (ed. J. Oates), World Archaeology, 24, 3, 361-378.

SNOdGrass, A. M. 1991: "Bronze Age Exchange: a Minimalist Position" en Bronze Age Trade in Mediterranean (ed. Gale), Studies in Mediterranean Archaeology, vol. XC, 15-20.

TYLECOTE, R. F., 1980: "Copper ingots and marine copper", The International Journal of Nautical Archaeology and Underwater Exploration, vol. 9, 1, 67-68.

VAGNETTI, L., 1992: "El comercio micénico con el Mediterráneo central: Italia peninsular y las islas", en el Mundo Micénico. Cinco siglos de la primera civilización europea, 1600-1100 a.C, Museo Arqueológico Nacional de Madrid, 106-109.

VAGNETTI, L., y Lo SCHIAVO, F., 1989: "Late Bronze Age long distance trade in the Mediterranean: the role of the Cypriots", Early Society in Cyprus, Edinburgh, 217-243.

WaCHSMANN, SH., y RaVEH, K., 1984: "Concerning a lead ingot fragment from ha-Hotrim, Israel", The International Journal of Nautical Archaeology and Underwater Exploration, 13, n. ${ }^{\circ}$ : 169-176.

WheEleR, T. S.; MAdDin, R., y Muhly, J. D., 1975: "Ingots and the Bronze Age Copper Trade in the Mediterranean: a progress report", Expedition, 17, 4, 31-39. 